\title{
Stroke risk, phenotypes, and death in COVID-19
}

Systematic review and newly reported cases

\author{
Sebastian Fridman, MD, MPH, Maria Bres Bullrich, MD, Amado Jimenez-Ruiz, MD, Pablo Costantini, MD, \\ Palak Shah, MD, Caroline Just, MD, Daniel Vela-Duarte, MD, MSCR, Italo Linfante, MD, FAHA, \\ Athena Sharifi-Razavi, MD, Narges Karimi, MD, Rodrigo Bagur, MD, PhD, Derek B. Debicki, MD, PhD, \\ Teneille E. Gofton, MD, David A. Steven, MD, MPH, and Luciano A. Sposato, MD, MBA
}

Neurology ${ }^{\circledR}$ 2020;95:e3373-e3385. doi:10.1212/WNL.0000000000010851

\section{Abstract \\ Objectives}

To investigate the hypothesis that strokes occurring in patients with coronavirus disease 2019 (COVID-19) have distinctive features, we investigated stroke risk, clinical phenotypes, and outcomes in this population.

\section{Methods}

We performed a systematic search resulting in 10 studies reporting stroke frequency among patients with COVID-19, which were pooled with 1 unpublished series from Canada. We applied random-effects meta-analyses to estimate the proportion of stroke among COVID-19. We performed an additional systematic search for cases series of stroke in patients with COVID-19 ( $\mathrm{n}=125)$, and we pooled these data with 35 unpublished cases from Canada, the United States, and Iran. We analyzed clinical characteristics and in-hospital mortality stratified into age groups $(<50,50-70,>70$ years). We applied cluster analyses to identify specific clinical phenotypes and their relationship with death.

\section{Results}

The proportions of patients with COVID-19 with stroke $(1.8 \%, 95 \%$ confidence interval [CI] $0.9 \%-3.7 \%)$ and in-hospital mortality $(34.4 \%, 95 \%$ CI $27.2 \%-42.4 \%)$ were exceedingly high. Mortality was $67 \%$ lower in patients $<50$ years of age relative to those $>70$ years of age (odds ratio [OR] 0.33, 95\% CI 0.12-0.94, $p=0.039$ ). Large vessel occlusion was twice as frequent $(46.9 \%)$ as previously reported and was high across all age groups, even in the absence of risk factors or comorbid conditions. A clinical phenotype characterized by older age, a higher burden of comorbid conditions, and severe COVID-19 respiratory symptoms was associated with the highest in-hospital mortality $(58.6 \%)$ and a 3 times higher risk of death than the rest of the cohort (OR 3.52, 95\% CI 1.53-8.09, $p=0.003$ ).

\section{Conclusions}

Stroke is relatively frequent among patients with COVID-19 and has devastating consequences across all ages. The interplay of older age, comorbid conditions, and severity of COVID-19 respiratory symptoms is associated with an extremely elevated mortality.

\author{
Correspondence \\ Dr. Sposato \\ Luciano.Sposato@ \\ LHSC.on.ca
}

\section{MORE ONLINE}

COVID-19 Resources

For the latest articles, invited commentaries, and blogs from physicians around the world NPub.org/COVID19

\footnotetext{
From the Department of Clinical Neurological Sciences (S.F., M.B.B., P.S., C.J., D.B.D., T.E.G., D.A.S., L.A.S.), Department of Medicine (R.B.), Division of Cardiology, Department of Anatomy and Cell Biology (L.A.S.), and Department of Epidemiology and Biostatistics (R.B., D.A.S., L.A.S.), Schulich School of Medicine and Dentistry, Heart \& Brain Laboratory (A.J.-R., L.A.S.), and Robarts Research Institute (L.A.S.), Western University, London, Ontario, Canada; Instituto de Neurología y Neurocirugía de Neuquén (P.C.), Argentina; Miami Cardiac \& Vascular Institute (D.V.-D., I.L.), Baptist Hospital Neuroscience Center, FL; Clinical Research Development Unit of Bou Ali Sina Hospital (A.S.-R.) and Immunogenetics Research Center (N.K.), Toxoplasmosis Research Center, Mazandaran University of Medical Sciences, Sari, Iran; and Lawson Health Research Institute (L.A.S.), London, Ontario, Canada.

Go to Neurology.org/N for full disclosures. Funding information and disclosures deemed relevant by the authors, if any, are provided at the end of the article.
} 


\section{Glossary}

CI = confidence interval; COVID-19 = coronavirus disease 2019; CVT = cerebral venous thrombosis; ICH = intracerebral hemorrhage; LVO = large vessel occlusion; OR = odds ratio; SAH = subarachnoid hemorrhage; SARS-CoV = severe acute respiratory syndrome coronavirus; $\mathbf{u O R}=$ unadjusted $\mathrm{OR}$.

Coronavirus disease 2019 (COVID-19) is a viral respiratory illness caused by the severe acute respiratory syndrome coronavirus (SARS-CoV) 2 and is associated with elevated risk of venous and arterial thrombotic events. ${ }^{1}$ Acute stroke has been reported among patients of all ages with COVID19. ${ }^{2}$ Specific concern has been raised about severe stroke occurring in young patients with COVID-19, some of them without preexisting risk factors. ${ }^{3}$ However, to date, relatively little is known about the frequency, clinical characteristics, and outcomes of acute cerebrovascular events in patients with COVID-19. We hypothesized that stroke is a frequent complication among patients with COVID-19, that in-hospital mortality is higher in patients with stroke and COVID-19 compared to historical cohorts without COVID-19, and that young patients would show a higher mortality due to a higher incidence of large vessel occlusion (LVO). We therefore investigated the incidence, characteristics, and outcomes of patients with COVID-19 with acute stroke.

\section{Methods}

\section{Standard protocol approvals, registrations, and patient consents}

This study was approved by the Western University Research Ethics Board. All patients from Canada, Iran, and the United States included in these series provided their informed consent.

\section{Objectives}

This study aimed (1) to estimate the risk of stroke among hospitalized patients with COVID-19; (2) to quantify inhospital mortality of patients with COVID-19 with stroke; (3) to analyze risk factor profiles, frequency of vascular comorbid conditions, subtypes, clinical characteristics, and outcomes of young patients with COVID-19 with stroke; (4) to derive clinical phenotypes of patients with stroke with COVID-19 based on unsupervised learning analyses; and (5) to compare in-hospital mortality between the derived clinical phenotypes.

\section{Proportion of hospitalized patients with COVID-19 with acute stroke}

To evaluate the proportion of patients with COVID-19 who sustained a stroke during either the presymptomatic or symptomatic period, we searched for publications reporting the number of cerebrovascular events (numerator) and the total number of patients admitted with COVID-19 (denominator). We identified potential studies by performing a systematic search of titles published in any language between
November 1, 2019, and May 29, 2020. We used PubMed, medRxiv, bioRxiv, and Research Square search engines. We did not develop a specific review protocol for this study, but we systematically listed all search terms (tables e-1-e-3, data available from Dryad, doi.org/10.5061/dryad.n5tb2rbt5) and documented them in a Preferred Reporting Items for Systematic Reviews and Meta-Analyses flowchart (figures e-1 and e-2, data available from Dryad). Five neurologists were randomly paired to review each abstract. One neurologist reviewed the selected articles and confirmed the presence of inclusion and exclusion criteria. We applied a random-effects meta-analysis to estimate the proportion of patients with COVID-19 experiencing a new stroke. The primary outcome was the occurrence stroke of any type, defined as ischemic stroke, intracerebral hemorrhage (ICH), cerebral venous thrombosis (CVT), or subarachnoid hemorrhage (SAH). The secondary outcome was the occurrence of an ischemic stroke. We used the Agresti-Cuoll method to calculate confidence intervals (CIs) for individual studies. We calculated between-study variance $\tau^{2}$ with the maximumlikelihood estimator. We reported the proportion and corresponding 95\% CIs of patients with COVID-19 with acute stroke by pooling data using the Hartung-Knapp approach. We quantitatively assessed the presence of between-study heterogeneity with $I^{2}$ (<25\% was considered low; $25 \%-50 \%$, moderate; and $>75 \%$, high) and $\chi^{2}$-based $\mathrm{Q}$ statistic (significant if $p<0.1$ ). We used the risk of bias in nonrandomized studies of interventions tool to assess the risk of bias and contour-enhanced funnel plots to assess publication bias. ${ }^{4}$

\section{In-hospital mortality}

To estimate the risk of death among hospitalized patients with COVID-19 with a new stroke occurrence, we performed an additional systematic search by applying the same search terms described for the above-mentioned meta-analysis. For these specific analyses, we looked for case reports and case series published in any language with full descriptions of clinical cases of patients with COVID-19 and stroke. COVID-19 diagnosis was defined as a confirmed positive PCR test or serology for SARS-CoV-2 with or without typical symptoms or radiographic findings. We included any case of stroke that occurred between 14 days before (COVID-19 incubation period estimated by the Centers for Disease Control $^{5}$ ) and 60 days after the diagnosis of COVID-19. We pooled the data resulting from the literature search with case series from the London Ontario Stroke Registry (London, Ontario, Canada), the Miami Cardiac \& Vascular Institute (Miami, FL), and the Mazandarn University of Medical Sciences (Sari, Mazandaran, Iran). We reported the 
risk of in-hospital mortality among patients with all stroke types and ischemic stroke as proportions and $95 \%$ CIs.

\section{Clinical characteristics and in-hospital mortality of young patients with COVID-19 with stroke}

We used the pooled dataset of case series and unpublished cases of COVID-19 and stroke to estimate the risk of inhospital mortality. We documented demographic data, risk factors, comorbid conditions, brain and vascular imaging findings, results of coagulation tests, and outcomes. We did not include data on duration of follow-up, stroke severity, mechanisms of ischemic strokes, medications, and length of hospital stay in this report because they were inconsistently and incompletely reported in the majority of the reviewed publications. If the severity of COVID-19 respiratory symptoms was not reported, we used any of the following criteria to define the disease as severe/critical: hypoxia, admission to the intensive care unit, or mechanical ventilation requirement. To investigate differences between young and older patients with COVID-19, we stratified patients into 3 age categories. Given discrepancies in the classification of patients with stroke as young, we chose the definition of $<50$ years of age used in a recent review article. ${ }^{6}$ Because some case series included in this analysis reported age decades instead of exact ages, ${ }^{7}$ we used a similar approach for classifying older age strata into 50 to 70 and $>70$ years. Accordingly, we defined age groups as young ( $<50$ years old), middle-aged ( $50-70$ years old), and older ( $>70$ years old). ${ }^{6}$ For the purpose of this analysis, the young category was the main age group of interest. The main outcome was in-hospital mortality. We quantified continuous variables as medians and interquartile ranges. We used $\chi^{2}$ and Mann-Whitney $U$ tests for comparing proportions and medians across the 3 age strata. We used 2-sided $z$ tests to compare proportions between 2 age groups. We estimated unadjusted odds ratios (uORs) and 95\% CIs for in-hospital mortality for young patients relative to the rest of the cohort.

\section{Clinical phenotyping of patients with COVID-19 with stroke}

We applied an unsupervised learning approach to develop clinical phenotypes of patients with COVID-19 with stroke by conducting agglomerative hierarchical cluster analyses, which allows for mitigating biases related to previously acquired non-COVID-19 stroke knowledge. ${ }^{8}$ The benefit of this approach is that patients are grouped into phenotypes or clusters based on common characteristics instead of classic categorization approaches (e.g., stratification in age groups), which could sometimes be arbitrary (e.g., defining the age cutoff for classifying a patient as young). We applied Gower distances with the maximum linkage clustering method. ${ }^{9}$ For the sake of dataset completeness, we included the covariables most consistently reported in case reports and case series (table 1). We used silhouette and C-index analyses to inform the total number of clusters. ${ }^{10}$ We decided the final number of clusters by applying clinical consensus between 2 coauthors (S.F. and L.A.S.). We created cluster heat maps to help understand the characteristics of each stroke phenotype in patients with COVID-19.

\section{Differences in in-hospital mortality across stroke phenotypes}

We compared proportions of in-hospital mortality among clinical phenotypes identified through unsupervised learning. For analyses resulting in 2 clusters, we estimated ORs and $95 \%$ CIs. For analyses resulting in $>2$ clusters, we identified the one with the highest in-hospital mortality and compared it against each of the remaining cohorts separately and as a single group by estimating ORs and 95\% CIs. We did not perform logistic regression analyses because all variables needed for the multivariable analysis were used to develop the clusters through unsupervised learning. We estimated the unadjusted risk of in-hospital mortality for all variables that were statistically more frequent in the clusters showing the highest in-hospital mortality.

We conducted all analyses with $\mathrm{R}$ version 3.6.2 ( $\mathrm{R}$ Core Team, Vienna, Austria, 2014). We used the Meta and Metaphor packages for the meta-analyses and Cluster and ClusterCrit for the cluster analyses.

\section{Data availability}

Data will be shared after ethics approval if requested by other investigators for purposes of replicating the results.

\section{Results}

\section{Proportion of patients with COVID-19 with stroke}

The systematic search for the meta-analysis of proportion of patients with COVID-19 experiencing a new stroke resulted in 2,628 titles, of which we reviewed 150 in full-text format (figure e-1, data available from Dryad, doi.org/10.5061/ dryad.n5tb2rbt5). The final cohort included a total of 3,306 patients with COVID-19 with stroke of any type and 5,322 with ischemic stroke from 10 studies and 1 newly reported cohort from Canada. Overall, 1.8\% (95\% CI 0.9\%-3.7\%) of patients with COVID-19 experienced a new stroke, and 1.5\% (95\% CI $0.8 \%-2.8 \%)$ had an ischemic stroke (figure 1 ). Heterogeneity between studies was high for the estimates of both any stroke $\left(I^{2}=84 \%, p<0.01\right)$ and ischemic stroke $\left(I^{2}=\right.$ $82 \%, p<0.01)$. The funnel plots were asymmetric, suggesting publication bias. The overall risk of bias was moderate (figure e-2, data available from Dryad).

\section{In-hospital mortality}

Among 2,628 unique titles identified in the search strategy of case reports and case series describing patients with COVID19 with stroke, we reviewed 252 in full-text format, resulting in the final inclusion of 42 studies (figure e-3, data available from Dryad, doi.org/10.5061/dryad.n5tb2rbt5) and 1 additional study that is currently under review. ${ }^{11}$ The total study cohort comprised 160 cases: 125 identified through the 
Table 1 Characteristics of 160 patients with COVID-19 with all types of stroke, stratified by age

\begin{tabular}{|c|c|c|c|c|c|}
\hline & \multirow[b]{2}{*}{ All patients $(n=160)$} & \multicolumn{3}{|l|}{ Age groups, y } & \multirow[b]{2}{*}{$p$ Value } \\
\hline & & $<50(n=29)$ & $50-70(n=74)$ & $>70(n=57)$ & \\
\hline \multicolumn{6}{|l|}{ Demographics } \\
\hline Median (IQR) age, y & $65.0(54.0,76.3)$ & $37.5(33.0,44.0)$ & $62.0(55.0,65.0)$ & $78.0(75.0,84.0)$ & $<0.001$ \\
\hline Female sex, n (\%) ${ }^{a}$ & $55(43.0)$ & $9(40.9)$ & $23(40.4)$ & $23(46.9)$ & 0.77 \\
\hline \multicolumn{6}{|l|}{ Risk factors, n (\%) } \\
\hline No risk factors & $26(16.4)$ & $13(44.8)$ & $8(11.0)$ & $5(8.8)$ & $<0.001$ \\
\hline Hypertension & $100(62.9)$ & $6(20.7)$ & $47(64.4)$ & $47(82.5)$ & $<0.001$ \\
\hline Diabetes mellitus & $65(40.9)$ & $10(34.5)$ & $31(42.5)$ & $24(42.1)$ & 0.74 \\
\hline Dyslipidemia & $44(27.7)$ & $6(20.7)$ & $21(28.8)$ & $17(29.8)$ & 0.64 \\
\hline Smoking & $12(7.5)$ & $1(3.4)$ & $7(9.6)$ & $4(7.0)$ & 0.56 \\
\hline \multicolumn{6}{|l|}{ Comorbid conditions, n (\%) } \\
\hline Previous stroke/TIA & $18(11.3)$ & $1(3.4)$ & $7(9.6)$ & $10(17.5)$ & 0.12 \\
\hline Atrial fibrillation & $24(15.1)$ & $0(0.0)$ & $12(16.4)$ & $12(21.1)$ & 0.033 \\
\hline Coronary artery disease & $28(17.6)$ & $1(3.4)$ & $11(15.1)$ & $16(28.1)$ & 0.013 \\
\hline Chronic kidney disease & $6(3.8)$ & $1(3.4)$ & $4(5.5)$ & $1(1.8)$ & 0.54 \\
\hline Obesity & $11(6.9)$ & $1(3.4)$ & $6(8.1)$ & $4(7.0)$ & 0.70 \\
\hline Cancer & $8(5.0)$ & $0(0.0)$ & $5(6.8)$ & $3(5.3)$ & 0.36 \\
\hline \multicolumn{6}{|l|}{ Clinical features of COVID-19 } \\
\hline Severe/critical COVID-19, n (\%) & $92(57.5)$ & $13(44.8)$ & $43(58.1)$ & $36(63.2)$ & 0.26 \\
\hline No COVID-19 symptoms before stroke, n (\%) & $49(30.8)$ & $14(48.3)$ & $17(23.3)$ & $18(31.6)$ & 0.047 \\
\hline Time from COVID-19 symptoms to stroke, $\mathrm{d}^{\mathrm{b}}$ & $8.0(5.0,15.0)$ & $8.0(7.0,14.0)$ & $12.0(5.3,17.8)$ & $5.0(3.0,10.0)$ & 0.08 \\
\hline \multicolumn{6}{|l|}{ Event type, n (\%) } \\
\hline Ischemic stroke & $126(78.8)$ & $22(75.9)$ & $57(77.0)$ & $47(82.5)$ & 0.69 \\
\hline Intracerebral hemorrhage & $24(15.0)$ & $4(13.8)$ & $10(13.5)$ & $10(17.5)$ & 0.80 \\
\hline Subarachnoid hemorrhage & $3(1.9)$ & $1(3.4)$ & $2(2.7)$ & $0(0.0)$ & 0.42 \\
\hline Cerebral venous thrombosis & $7(4.4)$ & $2(6.9)$ & $5(6.8)$ & $0(0.0)$ & 0.13 \\
\hline \multicolumn{6}{|l|}{ Laboratory findings, $n(\%)^{c}$} \\
\hline Elevated D-dimer & $96(82.1)$ & $20(90.9)$ & $46(80.7)$ & 30 (78.9) & 0.47 \\
\hline Positive APLA & $12(54.5)$ & $1(20.0)$ & $8(80.0)$ & $3(42.9)$ & 0.07 \\
\hline Prolonged PTT & $18(20.2)$ & $3(27.3)$ & $10(25.0)$ & $5(13.2)$ & 0.35 \\
\hline Thrombocytopenia & $12(11.2)$ & $1(6.7)$ & $8(16.7)$ & $3(6.8)$ & 0.27 \\
\hline Elevated fibrinogen & $35(85.4)$ & $8(66.7)$ & $19(95.0)$ & $8(88.9)$ & 0.09 \\
\hline Elevated cardiac troponin & $30(40.5)$ & $5(71.4)$ & $15(48.4)$ & $10(27.8)$ & 0.050 \\
\hline \multicolumn{6}{|l|}{ Outcomes, n (\%) } \\
\hline Venous thromboembolism ${ }^{d}$ & $11(11.8)$ & $2(10.0)$ & $6(13.6)$ & $3(10.3)$ & 0.88 \\
\hline Deceased & $55(34.4)$ & $6(20.7)$ & $24(32.4)$ & 25 (43.9) & 0.15 \\
\hline Home/rehabilitation & 68 (42.5) & $14(48.3)$ & $30(40.5)$ & $24(42.1)$ & \\
\hline
\end{tabular}


Table 1 Characteristics of 160 patients with COVID-19 with all types of stroke, stratified by age (continued)

\begin{tabular}{l} 
Still hospitalized \\
\hline Abbreviations: APLA = antiphospholipid antibodies; COVID-19 = coronavirus disease 2019; IQR = interquartile range; PTT = partial thromboplastin time. \\
a Data on sex were available for 128 patients. \\
b 27.0$)$ \\
'Data are median (IQR) days. \\
${ }^{\text {d } V e n o u s ~ t h r o m b o e m b o l i s m ~ i n c l u d e s ~ d e e p ~ v e n o u s ~ t h r o m b o s i s ~ a n d ~ p u l m o n a r y ~ e m b o l i s m . ~}$
\end{tabular}

systematic literature search, 5 from London (Canada), 29 from Sari (Iran), and 1 from Miami (FL) (table e-4, data available from Dryad). All 160 patients in this cohort were admitted to the hospital. Two of the cases from Sari were included in a case series accepted for publication after being incorporated into this dataset and when the systematic search was already closed. ${ }^{12}$ Among 6 patients with COVID-19 with stroke identified in London, 1 patients did not provide consent to have data included in the descriptive case series. None of these 160 cases except for 5 patients from London were included in the meta-analyses performed for estimating the occurrence of stroke in patients with COVID-19.

The median age was 65.0 (interquartile range 54.0, 76.3) years (table 1). Among 128 cases for whom information about sex was available, $55(43.0 \%)$ were female. The numbers of patients with ischemic stroke, ICH, CVT, and SAH were 126
(78.8\%), 24 (15.0\%), 7 (4.4\%), and 3 (1.9\%). There were 55 in-hospital deaths among patients with strokes of all types considered together $(34.4 \%, 95 \%$ CI $27.2 \%-42.4 \%)$ and 45 among 126 with ischemic strokes (35.7\%, 95\% CI $27.5 \%-44.8 \%)$. After the exclusion of patients who were still hospitalized and thus with uncertain outcome, there were 55 deaths among 123 patients with stroke (44.7\%, 95\% CI $35.9 \%-53.5 \%)$ and 45 deaths among 100 patients with ischemic stroke (45.0\%, 95\% CI 35.3\%-54.8\%).

\section{Young patients with COVID-19 with stroke of any type}

In the age-stratified descriptive analysis for 160 patients with all types of stroke (table 1), there were 29 who were $<50$ years of age. On unadjusted analyses, those $<50$ years of age were the ones most likely to have no previous risk factors or comorbid conditions $(42.9 \%, p<0.001)$, and

Figure 1 Proportion of patients with COVID-19 with any stroke and ischemic stroke

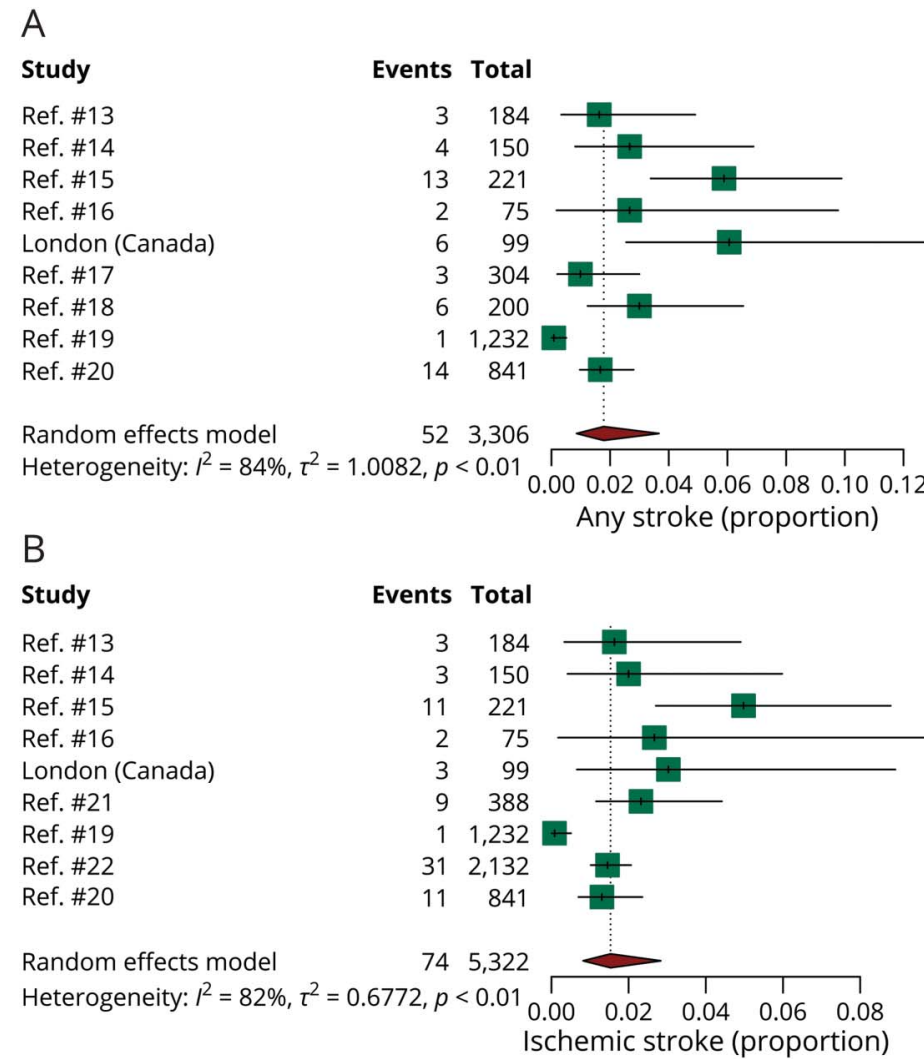

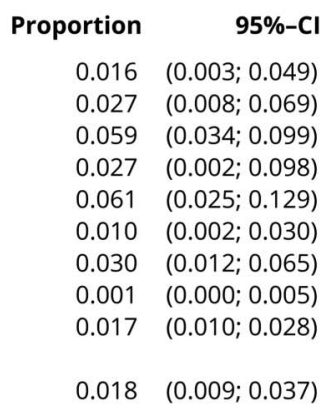

$\begin{array}{rr}\text { Proportion } & 95 \%-\mathrm{Cl} \\ 0.016 & (0.003 ; 0.049) \\ 0.020 & (0.004 ; 0.060) \\ 0.050 & (0.027 ; 0.088) \\ 0.027 & (0.002 ; 0.098) \\ 0.030 & (0.007 ; 0.089) \\ 0.023 & (0.012 ; 0.044) \\ 0.001 & (0.000 ; 0.005) \\ 0.015 & (0.010 ; 0.021) \\ 0.013 & (0.007 ; 0.024) \\ & \\ 0.015 & (0.008 ; 0.028)\end{array}$

(A) Random-effect meta-analysis for any stroke: ischemic stroke, intracerebral hemorrhage, cerebral venous thrombosis, and subarachnoid hemorrhage. (B) Random-effects meta-analysis for ischemic stroke. London (Canada) refers to unpublished cohort of patients admitted to London Health Sciences Centre, London, Ontario, Canada. $\mathrm{Cl}=$ confidence interval; COVID-19 = coronavirus disease 2019. 
they had the lowest frequency of hypertension $(20.7 \%, p<$ $0.001)$, atrial fibrillation $(0.0 \%, p=0.033)$, and coronary artery disease $(3.4 \%, p=0.013)$. Strokes in younger patients were most likely to occur before the onset of COVID-19 symptoms $(48.3 \%, p=0.047)$. There were no differences between age groups in the proportion of patients with severe or critical COVID-19 or in types of stroke. The most frequent laboratory finding was elevated D-dimer $(82.1 \%)$, although there were no significant differences compared to middle-aged or older groups. Young patients showed the highest frequency of cardiac troponin elevation $(71.4 \%, p=0.050)$. The unadjusted risk of inhospital death in patients $<50$ years of age was lower than among those $>70$ years of age (uOR 0.33 , 95\% CI $0.12-0.94, p=0.039$ ), but there were no differences in the risk of in-hospital death between young patients and the rest of the cohort (uOR 0.44, 95\% CI 0.16-1.15, $p=0.09$ ). The latter lack of significance is probably underpowered (power for 2-sided $\alpha$ of $0.5=51.9 \%$ ).

\section{Young patients with COVID-19 with ischemic stroke}

In the age-stratified descriptive analysis of 126 ischemic stroke cases, there were $22(17.4 \%)$ patients $<50$ years of age (table 2 ). Young patients with ischemic strokes were the age group with the highest proportion with no risk factors or comorbid conditions $(40.9 \%, p<0.001)$ and with the lowest prevalence of hypertension $(27.3 \%, p<0.001)$ and atrial fibrillation $(0.0 \%, p=0.048)$. Young patients were the most likely to experience an ischemic stroke in the absence of any prior COVID-19 respiratory symptoms $(50.0 \%, p=0.014)$ and to present with an LVO $(68.8 \%, p=0.049)$. Despite this, the risk young patients presenting with $\mathrm{LVO}$ was not higher than that of the rest of the cohort (uOR 2.46, 95\% CI 0.83-7.30, $p=$ 0.10 ). We found no differences between age groups in the proportion of patients receiving IV thrombolysis (tissue plasminogen activator) or mechanical thrombectomy. Patients with ischemic stroke who were $<50$ years of age showed the highest frequency of elevated cardiac troponin $(80.0 \%, p=$ $0.046)$. There were no differences in the unadjusted risk of death between young $(<50$ years of age) and older $(>70$ years of age) patients (uOR 0.48, 95\% CI 0.16-1.45, $p=0.19$ ) or between young patients and the rest of cohort ( $\mathrm{uOR} 0.63,95 \%$ CI $0.23-1.73, p=0.37$ ).

\section{Cluster analysis for all strokes}

The hierarchical cluster analysis for all strokes included 158 of 160 patients and resulted in 3 phenotypes (figure e-4, data available from Dryad, doi.org/10.5061/dryad.n5tb2rbt5). Two patients were excluded because of being outliers or having missing data. Cluster 1 had the lowest burden of hypertension, diabetes mellitus, and dyslipidemia, with $40.0 \%$ of cases in the cluster having no known risk factors or comorbid conditions (figure 2 and table e-5, data available from Dryad doi.org/10.5061/dryad.n5tb2rbt5). Cluster 1 was also the most heterogeneous in terms of types of strokes, including ischemic events, ICH, CVT, and SAH cases. Cluster 2 was the largest $(\mathrm{n}=82)$ and comprised exclusively ischemic stroke cases. It had an intermediate burden of risk factors and comorbid conditions and the lowest proportion of patients with severe or critical COVID-19 respiratory symptoms $(42.7 \%, p<0.001)$. Cluster 3 comprised the largest proportion of individuals $>70$ years old $(58.6 \%, p=0.006)$, the lowest percentage of young patients $(10.3 \%, p<0.001)$, and the highest burden of risk factors (e.g., hypertension, diabetes mellitus, and dyslipidemia) and cardiovascular comorbid conditions, including prior stroke or TIA $(27.6 \%, p=0001)$, atrial fibrillation $(41.4 \%, p$ $<0.001)$, and coronary artery disease $(37.9 \%, p=0.001)$. Almost all patients in cluster 3 had severe or critical COVID-19 respiratory symptoms $(96.9 \%, p<0.001)$.

\section{Cluster analysis for ischemic stroke}

The cluster analysis for ischemic stroke included 124 patients and resulted in 2 phenotypes (figure 3 and table e-6, data available from Dryad, doi.org/10.5061/dryad.n5tb2rbt5). Two patients were excluded because of being outliers or having missing data. Cluster 1 had a higher proportion of patients $<50$ years of age than cluster $2(28.9 \%$ vs $11.4 \%, p<$ $0.038)$ and a lower prevalence of atrial fibrillation $(6.7 \%$ vs $24.1 \%, p=0.028)$ and coronary artery disease $(6.7 \%$ vs $24.1 \%$, $p=0.028)$. The proportion of patients presenting with severe or critical COVD-19 respiratory symptoms was also lower in cluster 1 relative to cluster\#2 (6.7\% vs $94.2 \%, p<0.001)$. There were no additional significant differences between clusters except for a higher prevalence of chronic kidney disease in cluster $1(11.1 \%$ vs $0.0 \%, p=0.011)$.

\section{Differences in in-hospital mortality across stroke phenotypes}

In the analysis including all strokes, the proportion not surviving hospitalization was highest for cluster $3(58.6 \%, 95 \% \mathrm{CI}$ $40.7 \%-76.5 \%, p<0.001$ ) (table e-7, data available from Dryad, doi.org/10.5061/dryad.n5tb2rbt5). In-hospital mortality of cluster 3 was higher than that of cluster 1 (odds ratio [OR] 4.63, 95\% CI 1.70-12.6, $p=0.003$ ) and cluster 2 (OR $3.05,95 \%$ CI 1.27-7.31, $p=0.012$ ). Compared to clusters 1 and 2 considered together, patients in cluster 3 had a higher risk of in-hospital death (OR 3.52, 95\% CI 1.53 to $8.09, p=$ 0.003 ). Among the variables showing significant differences between cluster 3 and other clusters, the only one associated with in-hospital mortality was the severity of COVID-19 respiratory symptoms (OR 6.56, 95\% CI 2.91-14.76, $p<0.001$ ) (table e-8, data available from Dryad).

In the analysis limited to patients with ischemic stroke, cluster 2 was the one with the highest in-hospital mortality (48.1\%, 95\% CI $37.1 \%-59.1 \%, p<0.001$ ) (table e-9, data available from Dryad, doi.org/10.5061/dryad.n5tb2rbt5). This risk was higher than that of cluster 1 (OR 6.02, 95\% CI 2.29-15.83, $p<$ 0.001 ). Among the variables showing significant differences between clusters 2 and 1, the only one associated with inhospital mortality was the severity of COVID-19 respiratory symptoms (OR 9.51, 95\% CI 3.41-26.58, $p<0.001$ ) (table e-10, data available from Dryad). 
Table 2 Characteristics of 126 patients with COVID-19 with ischemic stroke, stratified by age

\begin{tabular}{|c|c|c|c|c|c|}
\hline & \multirow[b]{2}{*}{ All patients $(n=126)$} & \multicolumn{3}{|l|}{ Age groups, y } & \multirow[b]{2}{*}{$p$ Value } \\
\hline & & $<50(n=22)$ & $50-70(n=56)$ & $>70(n=48)$ & \\
\hline \multicolumn{6}{|l|}{ Demographics } \\
\hline Median (IQR) age, y & $65.0(54.0,76.3)$ & $37.5(33.0,44.0)$ & $62.0(55.0,65.0)$ & $78.0(75.0,84.0)$ & $<0.001$ \\
\hline Female sex, $n(\%)^{a}$ & $44(46.8)$ & $7(46.7)$ & $16(40.0)$ & $21(53.8)$ & 0.47 \\
\hline \multicolumn{6}{|l|}{ Risk factors, n (\%) } \\
\hline No risk factors & $16(12.8)$ & $9(40.9)$ & $5(8.9)$ & $2(4.3)$ & $<0.001$ \\
\hline Hypertension & 85 (68.0) & $6(27.3)$ & 38 (67.9) & $41(87.2)$ & $<0.001$ \\
\hline Diabetes mellitus & $56(44.8)$ & $9(40.9)$ & $25(44.6)$ & $22(46.8)$ & 0.90 \\
\hline Dyslipidemia & $41(32.8)$ & $6(27.3)$ & $20(35.7)$ & 15 (31.9) & 0.76 \\
\hline Smoking & $9(7.2)$ & $1(4.5)$ & $5(8.9)$ & $3(6.4)$ & 0.77 \\
\hline \multicolumn{6}{|l|}{ Comorbid conditions, n (\%) } \\
\hline Previous stroke/TIA & $15(12.0)$ & $1(4.5)$ & $7(12.5)$ & $7(14.9)$ & 0.46 \\
\hline Atrial fibrillation & $23(18.4)$ & $0(0.0)$ & $12(21.4)$ & $11(23.4)$ & 0.048 \\
\hline Coronary artery disease & $23(18.4)$ & $1(4.5)$ & $9(16.1)$ & $13(27.7)$ & 0.06 \\
\hline Chronic kidney disease & $6(4.8)$ & $1(4.5)$ & $4(7.1)$ & $1(2.1)$ & 0.49 \\
\hline Obesity & $9(7.1)$ & $1(4.5)$ & $5(8.8)$ & $3(6.4)$ & 0.78 \\
\hline Cancer & $5(4.0)$ & $0(0.0)$ & $3(5.4)$ & $2(4.3)$ & 0.55 \\
\hline \multicolumn{6}{|l|}{ Clinical features of COVID-19 } \\
\hline Severe/critical COVID-19, n (\%) & 77 (61.1) & $10(45.5)$ & $36(63.2)$ & $31(66.0)$ & 0.24 \\
\hline No COVID-19 symptoms before stroke, $n$ (\%) & $37(29.6)$ & $11(50.0)$ & $10(17.9)$ & $16(34.0)$ & 0.014 \\
\hline Time from COVID-19 symptoms to stroke, $\mathrm{d}^{\mathrm{b}}$ & $8.0(5.0,15.0)$ & $8.0(7.0,14.0)$ & $12.0(5.3,17.8)$ & $5.0(3.0,10.0)$ & 0.18 \\
\hline \multicolumn{6}{|l|}{ Vascular and brain imaging, $\mathrm{n}(\%)$} \\
\hline Large vessel occlusion ${ }^{c}$ & $46(46.9)$ & $11(68.8)$ & $14(34.1)$ & $21(51.2)$ & 0.049 \\
\hline Infarct limited to the left side & $30(32.3)$ & $6(40.0)$ & $15(38.5)$ & $9(23.1)$ & 0.27 \\
\hline Infarct limited to the right side & $42(45.2)$ & $9(60.0)$ & $13(33.3)$ & $20(51.3)$ & 0.13 \\
\hline Bilateral infarcts & $20(21.5)$ & $0(0.0)$ & $11(28.2)$ & $9(23.1)$ & 0.07 \\
\hline Middle cerebral artery territory & $72(76.6)$ & $12(80.0)$ & $33(82.5)$ & $27(69.2)$ & 0.36 \\
\hline Anterior cerebral artery territory & $8(8.5)$ & $1(6.7)$ & $4(10.0)$ & $3(7.7)$ & 0.90 \\
\hline Posterior cerebral artery territory & $12(12.8)$ & $1(6.7)$ & $6(15.0)$ & $5(12.8)$ & 0.71 \\
\hline Vertebrobasilar territory & $17(18.1)$ & $1(6.7)$ & $7(17.5)$ & $9(23.1)$ & 0.37 \\
\hline Multiple territories & $29(30.9)$ & $1(6.7)$ & $15(37.5)$ & $13(33.3)$ & 0.08 \\
\hline \multicolumn{6}{|l|}{ Laboratory findings, $n(\%)^{d}$} \\
\hline Elevated D-dimer & $86(82.7)$ & $18(90.0)$ & $40(81.6)$ & $28(80.0)$ & 0.62 \\
\hline Positive APLA & $11(64.7)$ & $1(33.3)$ & $7(87.5)$ & $3(50.0)$ & 0.16 \\
\hline Prolonged PTT & $14(22.2)$ & $3(37.5)$ & $7(26.9)$ & $4(13.8)$ & 0.27 \\
\hline Thrombocytopenia & $8(10.1)$ & $0(0.0)$ & $5(14.7)$ & $3(8.8)$ & 0.35 \\
\hline Elevated fibrinogen & $32(88.9)$ & $8(72.7)$ & $16(94.1)$ & $8(100.0)$ & 0.11 \\
\hline Elevated cardiac troponin & $28(45.2)$ & $4(80.0)$ & $14(56.0)$ & $10(31.2)$ & 0.046 \\
\hline
\end{tabular}


Table 2 Characteristics of 126 patients with COVID-19 with ischemic stroke, stratified by age (continued)

\begin{tabular}{|c|c|c|c|c|c|}
\hline & \multirow[b]{2}{*}{ All patients $(n=126)$} & \multicolumn{3}{|c|}{ Age groups, y } & \multirow[b]{2}{*}{$p$ Value } \\
\hline & & $<50(n=22)$ & $50-70(n=56)$ & $>70(n=48)$ & \\
\hline \multicolumn{6}{|l|}{ Treatment, n (\%) } \\
\hline IV tissue plasminogen activator & $16(12.9)$ & $6(28.6)$ & $5(8.9)$ & $5(10.6)$ & 0.06 \\
\hline Mechanical thrombectomy & $15(12.1)$ & $3(14.3)$ & $7(12.5)$ & $5(10.6)$ & 0.91 \\
\hline \multicolumn{6}{|l|}{ Outcomes, n (\%) } \\
\hline Venous thromboembolism ${ }^{e}$ & $9(13.0)$ & $1(7.1)$ & $5(15.6)$ & $3(13.0)$ & 0.73 \\
\hline Deceased & $45(35.7)$ & $6(27.3)$ & $18(31.6)$ & $21(44.7)$ & 0.36 \\
\hline Home/Rehabilitation & $55(43.7)$ & $11(50.0)$ & $24(42.1)$ & $20(42.6)$ & \\
\hline Still hospitalized & $26(20.6)$ & $5(22.7)$ & $15(26.3)$ & $6(12.8)$ & \\
\hline \multicolumn{6}{|c|}{ 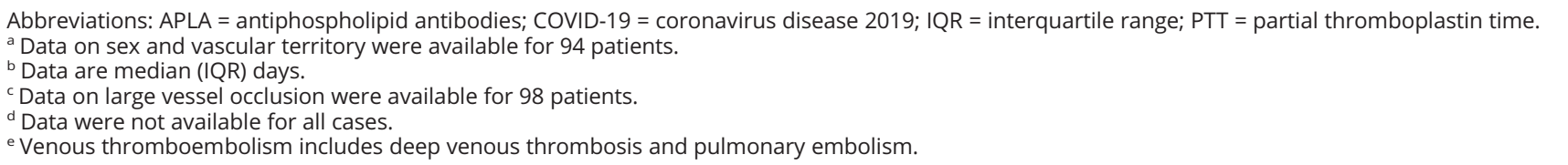 } \\
\hline
\end{tabular}

\section{Discussion}

Several findings from this study investigating stroke risk, characteristics, and outcomes among patients with COVID-19 deserve discussion (figure 4). Consistent with the main study hypothesis, the proportion of patients with COVID-19 experiencing a stroke was high relative to patients with other viral respiratory diseases. In-hospital mortality was exceedingly high for patients with COVID-19 with strokes of any type and ischemic stroke. In-hospital mortality was higher for young patients with COVID-19 with stroke of any type than for those $>70$ years of age. However, this was not found among patients with ischemic stroke. The presence of LVO was high across all ages but was not statistically significantly higher for the youngest age group. By applying unsupervised learning, we identified specific phenotypes of patients with COVID-19 with stroke, characterized by the interplay of older age, cardiovascular comorbid conditions, and severe COVID19 respiratory symptoms, which were associated with increased risk of death. The severity of COVID-19 respiratory symptoms was the factor most strongly associated with stroke mortality.

We found that the occurrence of stroke among hospitalized patients with COVID-19 was relatively high $(1.8 \%$, $95 \%$ CI $0.9 \%-3.7 \%$ ) compared to patients with other viral respiratory infections or even sepsis. We found similar results in the meta-analysis for ischemic stroke $(1.6 \%, 95 \% \mathrm{CI}$ $0.8 \%-2.8 \%)$. The observed risk of stroke was double that reported in patients with SARS-CoV-1 $(0.75 \%)^{23}$ or severe sepsis $(0.78 \%){ }^{24}$ The risk of ischemic stroke was 8 times higher than that reported among hospitalized patients with influenza $(0.2 \%))^{25}$ Although high, these numbers likely constitute an underestimate of the actual frequency of stroke among patients with COVID-19 because of missed stroke diagnoses in those who were not extubated after prolonged periods or did not survive mechanical ventilation. ${ }^{26}$ The lack of autopsies ${ }^{27}$ and restrictions on investigations related to safety recommendations ${ }^{28}$ or hospital policies may have contributed to further underestimation of the risk of stroke among hospitalized patients with COVID-19. Furthermore, the well-recognized drop in the number of patients with acute cerebrovascular symptoms seeking medical attention in the COVID-19 era also may have contributed to the underestimation of the frequency of stroke occurrence in this population. $^{29}$

In-hospital mortality was remarkably high for the whole cohort $(\approx 35 \%)$ and even higher $(\approx 45 \%)$ after the exclusion of patients whose outcome was undetermined at the time their cases were reported (e.g., those who were still admitted). Inhospital mortality in this cohort of patients with COVID-19, which comprised mainly cases with ischemic stroke, was higher than recently reported in a cohort of patients with COVID-19 with acute ischemic stroke (27.6\%). ${ }^{30}$ It was also higher than reported 30-day case fatality rates for ischemic stroke, ranging from $9 \%$ to $19 \%,{ }^{31}$ or in-hospital mortality of patients with stroke admitted to intensive care units, ranging between $14.7 \%$ and $21.9 \%{ }^{32,33}$ It must be noted that the limited testing in several countries may have led to inflation of death rates. The elevated incidence of potentially fatal thrombotic complications in patients with COVID-19 and stroke could have contributed to their increased risk of death. Indeed, we found that the combination of deep vein thrombosis and pulmonary embolism was frequent among patients with COVID-19 with stroke, affecting $\approx 11 \%$ and $\approx 13 \%$ of all strokes and ischemic strokes. This number is $>10$ times higher than the reported incidence of pulmonary embolism within 30 days of ischemic stroke occurrence in a Canadian population-based study 
$(0.78 \%) .{ }^{24}$ Pulmonary embolism also may explain paradoxical embolism in patients with COVID-19 with ischemic stroke, as recently documented in 2 COVID-19 cases showing a thrombus in transit through a patent foramen ovale. ${ }^{35,36}$

Patients $<50$ years of age with any stroke or ischemic stroke had the lowest prevalence of hypertension and atrial fibrillation compared to other age groups. Young patients with stroke of any type also had the lowest prevalence of coronary artery disease. Approximately $50 \%$ of patients $<50$ years of age experienced their strokes before the onset of COVID-19 respiratory symptoms, and this was significantly more frequent than in other age groups. This finding may imply that, in the COVID-19 era, younger patients presenting to the emergency department with acute stroke would need to be tested for SARS-CoV-2 even in the absence of specific symptoms or regardless of having passed a COVID-19 screen.

The frequency of LVO was highest among young patients $(68.8 \%)$. However, this difference was marginally significant
( $p=0.049$ ), and the unadjusted odds of young patients for presenting more frequently with an LVO than the rest of the cohort was nonsignificant (uOR 2.46, 95\% CI 0.83-7.30, $p=$ $0.10)$. This may be due to the lack of adjustment, the study sample size, or publication bias. In addition, the nonsignificant differences in the proportion of patients presenting with LVO could be due to a consistently high prevalence of LVO across all age groups. Indeed, the observed overall $46.9 \%$ prevalence of LVO in the whole cohort of patients with ischemic stroke was almost twice as high as the $29.2 \%$ recently reported in a population-based study. ${ }^{37}$ Similarly, $68.8 \%$ of patients with ischemic stroke who were $<50$ years of age in our study had an LVO compared to $29.7 \%$ in the same population-based study. ${ }^{37}$ The high prevalence of LVO in the context of a low burden of comorbid conditions in young patients with COVID-19 with stroke strongly supports the role of hypercoagulability as a cause of arterial thrombosis in this age group. This concept is further reinforced by the $>4$ times higher proportion of cases with elevated D-dimer in our cohort of patients with ischemic stroke (82.7\%), particularly

Figure 2 Main characteristics of clinical phenotypes of all strokes derived from unsupervised learning
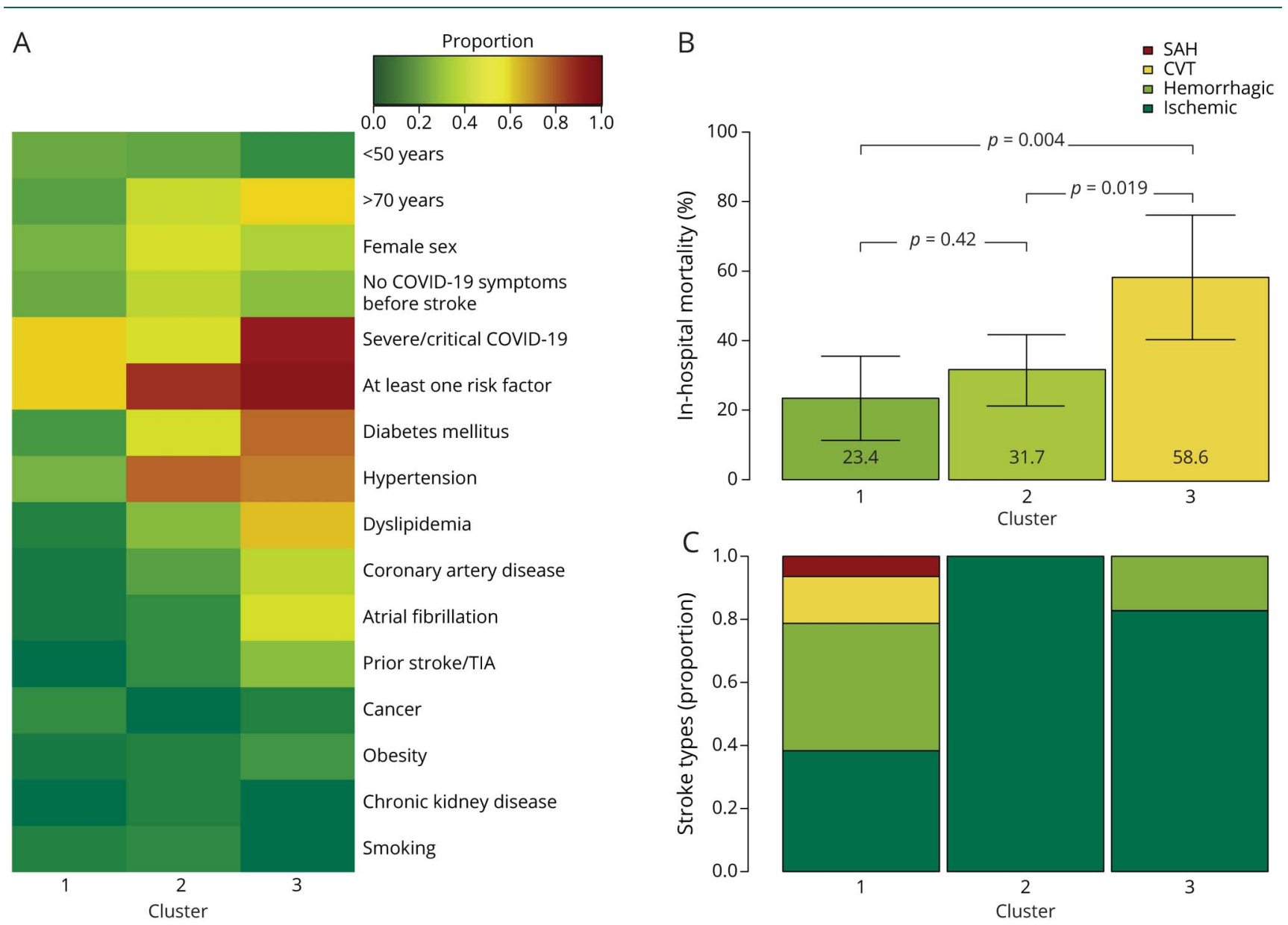

(A) Heat map showing relative frequencies of main characteristics of each stroke phenotype. Heat map shows the salient characteristics of cluster 3 , with the highest proportion of severe coronavirus disease 2019 (COVID-19) respiratory symptoms, diabetes mellitus, hypertension, dyslipidemia, atrial fibrillation, coronary artery disease, and previous stroke, all showing significant differences compared to other clusters. (B) Main subtype of stroke by clinical phenotype. (C) In-hospital mortality by clinical phenotypes. Data on outcomes were not used to develop the clusters. CVT = cerebral venous thrombosis; SAH = subarachnoid hemorrhage. 

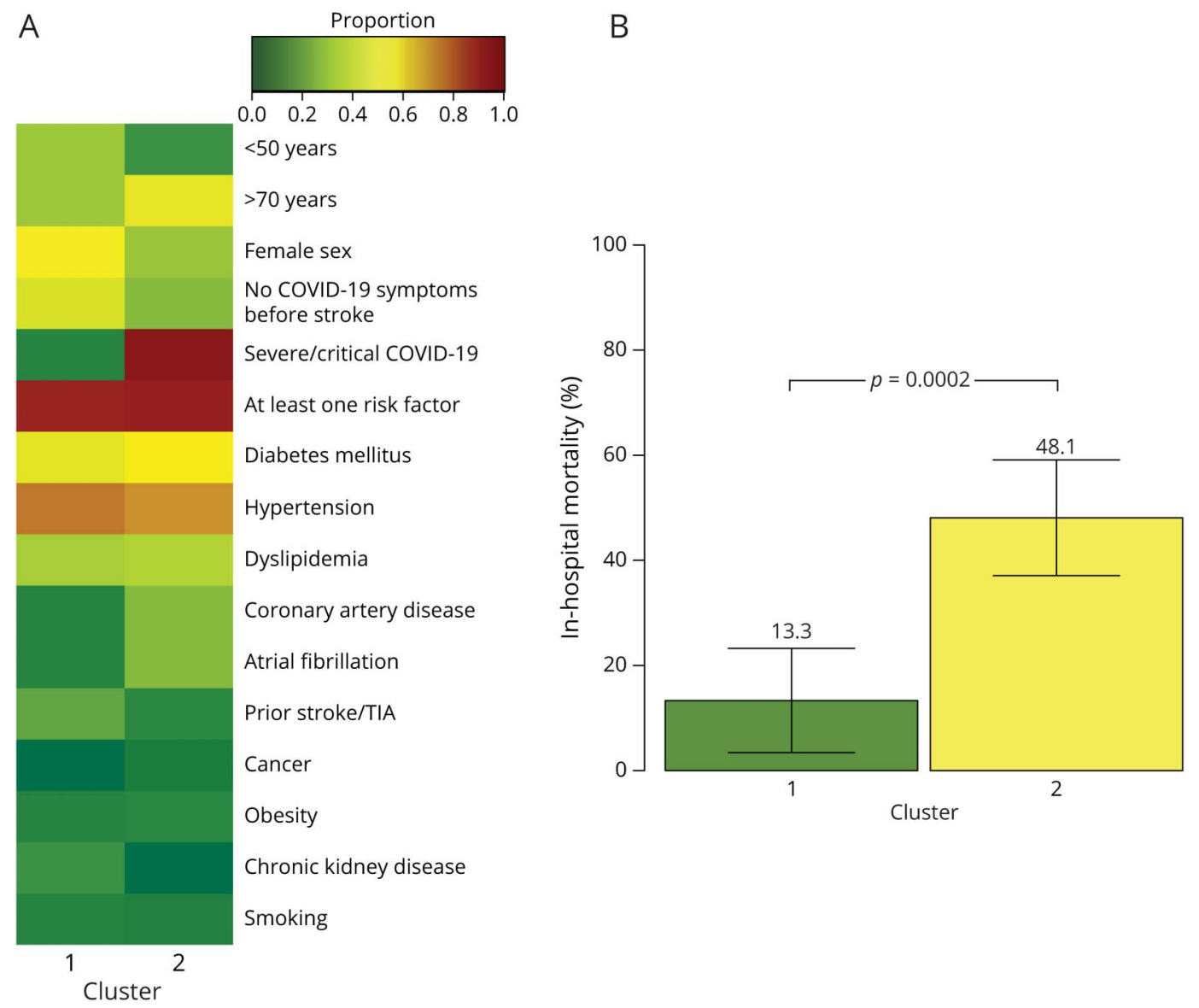

(A) Heat map showing relative frequencies of main characteristics of each ischemic stroke phenotype. (B) In-hospital mortality by clinical phenotypes. Data on outcomes were not used to develop the clusters. COVID-19 = coronavirus disease 2019.

among young patients (90.0\%), compared to the overall reported prevalence among patients with COVID-19 $(20.4 \%){ }^{38}$ Furthermore, recent reports of free-floating thrombi in the carotid ${ }^{39}$ or aortic ${ }^{40,41}$ arteries of patients with COVID-19 without structural vessel wall abnormalities such as plaque ulceration, inflammation, or hemorrhage $e^{29,30}$ suggest that COVID-19-related hypercoagulability could cause arterial thrombosis and embolism in the absence of underlying arterial wall disease. Only 3 of 11 (27\%) young patients with an LVO received a mechanical thrombectomy. Considering that $50 \%$ of young patients with acute ischemic stroke had no COVID-19 respiratory symptoms before stroke onset, it is possible that some patients decided to stay home instead of seeking medical attention because of concerns of being exposed to SARS-CoV-2 in the emergency room. ${ }^{29}$

Patients with ischemic stroke who were $<50$ years of age showed the highest frequency of elevated cardiac troponin $(80.0 \%, p=0.046)$. Increased cardiac troponin is a marker of either acute or chronic myocardial injury ${ }^{42}$ and is strongly associated with the risk of stroke. ${ }^{43}$ In the general population, factors most consistently associated with chronic myocardial injury are vascular risk factors and cardiovascular comorbid conditions such as atrial fibrillation and coronary artery disease. $^{42}$ In patients with stroke, elevated cardiac troponin is explained by either chronic (secondary to baseline underlying heart disease) or acute (neurogenically mediated or type 2 myocardial ischemia) myocardial injury. Considering that $44.8 \%$ of young patients with ischemic stroke in this cohort had no prior risk factors and that cardiac troponin was elevated in $80 \%$ of them, high troponin levels are likely the consequence of acute myocardial injury, which could play a role in the pathophysiology of acute ischemic stroke in young patients with COVID-19. This is further supported by the higher proportion of elevated cardiac troponin found in young patients with COVID-19 with ischemic stroke (80\%) compared to historical cohorts of patients with ischemic stroke $(40 \%)^{44}$ and to other age groups in this cohort. Furthermore, a recent study showed that although only 5\% of recovered patients had significantly elevated troponin levels at a median of 71 days after COVID-19 diagnosis, $78 \%$ had ongoing cardiac involvement and $60 \%$ had signs of myocardial inflammation on cardiac MRI. ${ }^{45}$ This suggests that myocarditis is a potential stroke mechanism in COVID-19. ${ }^{45}$ 
Stroke risk, clinical phenotypes, and outcomes in patients with COVID-19

Patients with COVID-19 and stroke $(N=160)$

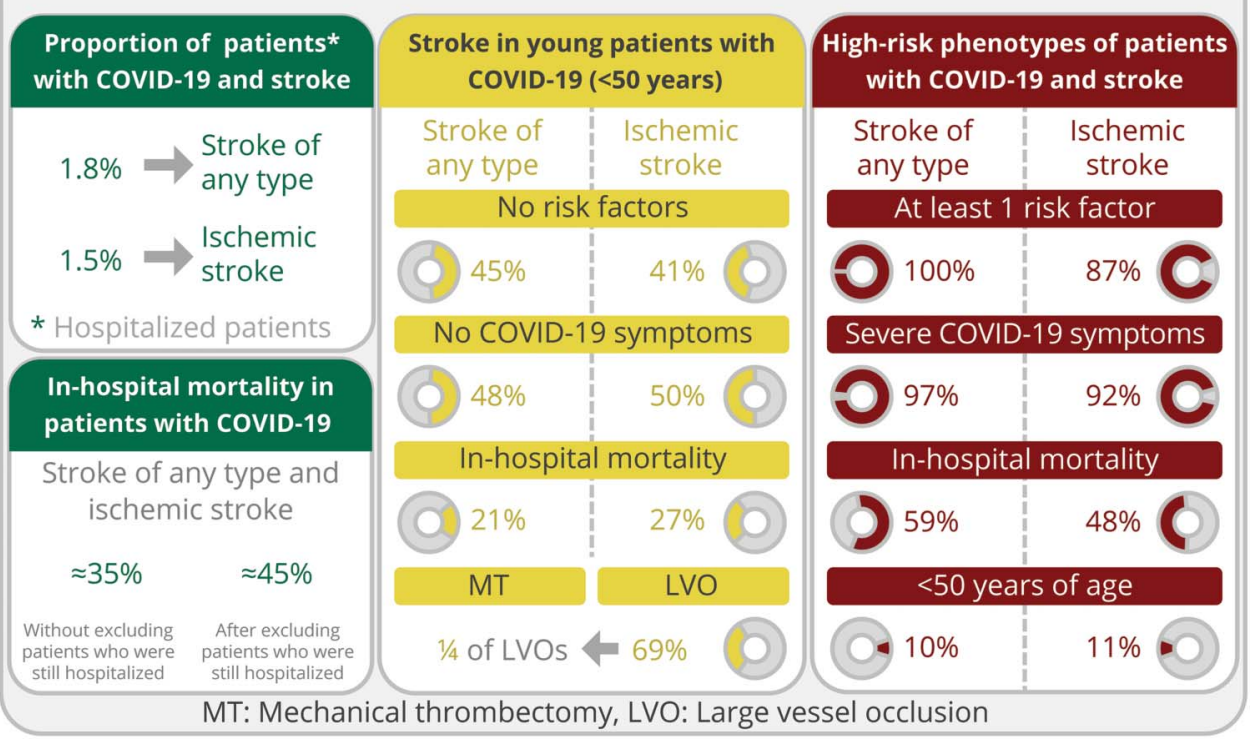

We identified specific stroke phenotypes consistently associated with increased mortality. Among patients with any stroke, cluster 3 was associated with $>3$ times higher inhospital mortality than each of the remaining 2 clusters or both of them considered together. This stroke phenotype was characterized by the interplay of older age, a higher burden of risk factors and comorbid conditions, and a higher proportion of severe or critical COVID-19 cases. Among these variables, the only one significantly associated with in-hospital mortality on unadjusted univariable analyses was severe COVID-19 respiratory symptoms (OR 6.56, 95\% CI 2.91-14.76, $p<$ 0.001 ). Thus, COVID-19 severity likely plays a major role in the risk of death of patients with stroke. Similar results were found among patients with ischemic stroke.

This work represents a comprehensive review of available evidence addressing the relationship between COVID-19 and stroke based on a large number of cases identified through a systematic search and pooled with previously unpublished cases. Our results should be interpreted in the context of the study limitations. First, although the study sample is relatively large, its size still precludes multivariable regression analyses for ischemic strokes. Second, because most of the source data were pooled from case series and reports, completeness was not ideal. As a consequence, we were not able to inform about stroke severity (only a few studies reported NIH Stroke Scale scores), stroke mechanisms, regional differences, social determinants of health, or race. Third, we found moderate publication bias (funnel plots and risk of bias in nonrandomized studies of interventions tool). Due to the relatively low number of studies included in the meta-analyses, funnel plots could have underestimated the risk of bias. Fourth, data used in this study are likely subject to the consequences of publication bias (e.g., reporting more severe cases or cases of LVO in young patients). Fifth, these results may not be generalizable to other populations such as nonhospitalized patients. To mitigate these limitations and the previous knowledge bias about stroke in patients without COVID-19, we implemented an unsupervised learning approach by applying cluster analyses, which allowed us to establish clinical phenotypes associated with increased risk of death. This was possible by comprehensive documentation of other important variables. Rather than focusing on single variables and their individual association with outcomes, these analyses allowed the characterization of the interplay of clinical characteristics, risk factors, demographics, and comorbid conditions as a whole and their association with in-hospital mortality.

We found that the frequency of stroke occurrence is high among hospitalized patients with COVID-19. In-hospital mortality is also exceedingly higher than previously reported in patients without COVID-19 with stroke. LVO is twice as frequent as previously reported, and its prevalence is high across all age groups, even in the absence of risk factors or comorbid conditions, suggesting the role of COVID-19related hypercoagulability. Specific clinical phenotypes characterized by the interplay of older age, a higher burden of cardiovascular comorbid conditions, and severe COVID-19 respiratory symptoms were associated with a substantial increase in the risk of death. COVID-19 severity seems to be the major determinant of death. Our findings should serve as information for guiding prognostication, resource allocation, and counseling of patients and their families. 


\section{Study funding}

L.A. Sposato is supported by the Kathleen \& Dr. Henry Barnett Research Chair in Stroke Research (Western University, London, Canada); the Edward and Alma Saraydar Neurosciences Fund (London Health Sciences Foundation, London, Canada); and the Opportunities Fund of the Academic Health Sciences Centre Alternative Funding Plan of the Academic Medical Organization of Southwestern Ontario (Ontario, Canada).

\section{Disclosure}

S. Fridman, M.B. Bullrich, A. Jimenez Ruiz, P. Costantini, and P. Shah have nothing to disclose. C. Just's Epilepsy \& Electroencephalography Fellowship is funded by UCB Pharma through the Canadian League Against Epilepsy (CLAE Epilepsy Post-Graduate Training Fellowship Award). D. VelaDuarte, I. Linfante, A. Sharifi-Razavi, N. Karimi, R. Bagur, D.B. Debicki, and T.E. Gofton have nothing to disclose. D.A. Steven reports receiving educational funding from Livanova Canada. L.A. Sposato reports speaker honoraria from Boehringer Ingelheim, Pfizer, Gore, and Bayer and research/quality improvement grants from Boehringer Ingelheim and Bayer. L.A. Sposato is member of the Editorial Board of Neurology, Stroke, and World Stroke Academy. Go to Neurology.org/N for full disclosures.

\section{Publication history}

Received by Neurology June 9, 2020. Accepted in final form August 25, 2020.

\section{Appendix Authors}

\begin{tabular}{|c|c|c|}
\hline Author & Locations & Contributions \\
\hline $\begin{array}{l}\text { Sebastian } \\
\text { Fridman, } \\
\text { MD, MPH }\end{array}$ & $\begin{array}{l}\text { Department of Clinical } \\
\text { Neurologic Sciences, } \\
\text { London Health Sciences } \\
\text { Center, Western University, } \\
\text { Ontario, Canada }\end{array}$ & $\begin{array}{l}\text { Designed and supervised } \\
\text { the study, planned and } \\
\text { performed the statistical } \\
\text { analyses, reviewed the } \\
\text { systematic search, } \\
\text { contributed to drafting the } \\
\text { first version of the } \\
\text { manuscript, and reviewed } \\
\text { the manuscript for } \\
\text { intellectual content }\end{array}$ \\
\hline
\end{tabular}

\begin{tabular}{lll}
\hline $\begin{array}{l}\text { Maria Bres } \\
\text { Bullrich, } \\
\text { MD }\end{array}$ & $\begin{array}{l}\text { Department of Clinical } \\
\text { Neurologic Sciences, } \\
\text { London Health Sciences } \\
\text { Center, Western University, } \\
\text { Ontario, Canada }\end{array}$ & $\begin{array}{l}\text { Performed the systematic } \\
\text { search, contributed to } \\
\text { drafting the first version of } \\
\text { the manuscript, and } \\
\text { reviewed the manuscript } \\
\text { for intellectual content }\end{array}$ \\
\hline $\begin{array}{l}\text { Amado } \\
\text { Jimenez- }\end{array}$ & $\begin{array}{l}\text { Heart \& Brain Laboratory, } \\
\text { Ruiz, MD }\end{array}$ & $\begin{array}{l}\text { Performed the systematic } \\
\text { Ontario, Canada }\end{array}$ \\
& & $\begin{array}{l}\text { search, contributed to } \\
\text { drafting the first version of } \\
\text { the manuscript, and } \\
\text { reviewed the manuscript } \\
\text { for intellectual content }\end{array}$ \\
\hline $\begin{array}{l}\text { Pablo } \\
\text { Costantini, } \\
\text { MD }\end{array}$ & $\begin{array}{l}\text { Instituto de Neurología y } \\
\text { Argentina }\end{array}$ & $\begin{array}{l}\text { Performed the systematic } \\
\text { search, contributed to } \\
\text { drafting the first version of } \\
\text { the manuscript, and }\end{array}$ \\
& & $\begin{array}{l}\text { reviewed the manuscript } \\
\text { for intellectual content }\end{array}$
\end{tabular}

Appendix (continued)

\begin{tabular}{lll}
\hline Author & Locations & Contributions \\
\hline $\begin{array}{l}\text { Palak Shah, } \\
\text { MD }\end{array}$ & $\begin{array}{l}\text { Department of Clinical } \\
\text { Neurologic Sciences, } \\
\text { London Health Sciences } \\
\text { Center, Western University, } \\
\text { Ontario, Canada }\end{array}$ & $\begin{array}{l}\text { Gathered data, reviewed } \\
\text { the manuscript for } \\
\text { intellectual content }\end{array}$ \\
& $\begin{array}{ll}\text { Department of Clinical } \\
\text { Just, MD }\end{array}$ & $\begin{array}{l}\text { Gathered data, reviewed } \\
\text { the manuscript for } \\
\text { Neurologic Sciences, } \\
\end{array}$ \\
& $\begin{array}{l}\text { London Health Sciences } \\
\text { Center, Western University, }\end{array}$ & \\
& Ontario, Canada &
\end{tabular}

\begin{tabular}{lll}
\hline $\begin{array}{l}\text { Daniel } \\
\text { Vela- } \\
\text { Duarte, } \\
\text { MD, MSCR }\end{array}$ & $\begin{array}{l}\text { Miami Cardiac \& Vascular } \\
\text { Institute, Baptist Hospital } \\
\text { Neuroscience Center, FL }\end{array}$ & $\begin{array}{l}\text { Gathered data, reviewed } \\
\text { the manuscript for } \\
\text { intellectual content }\end{array}$ \\
\hline $\begin{array}{l}\text { Italo } \\
\text { Linfante, } \\
\text { MD }\end{array}$ & $\begin{array}{l}\text { Miami Cardiac \& Vascular } \\
\text { Institute, Baptist Hospital } \\
\text { Neuroscience Center, FL }\end{array}$ & $\begin{array}{l}\text { Gathered data, reviewed } \\
\text { the manuscript for } \\
\text { intellectual content }\end{array}$ \\
\hline $\begin{array}{l}\text { Athena } \\
\text { Sharifi- } \\
\text { Razavi, MD }\end{array}$ & $\begin{array}{l}\text { Clinical Research } \\
\text { Development Unit of Bou- } \\
\text { Ali Sina Hospital, } \\
\text { Mazandaran University of }\end{array}$ & $\begin{array}{l}\text { Gathered data, reviewed } \\
\text { the manuscript for } \\
\text { intellectual content }\end{array}$ \\
& $\begin{array}{l}\text { Medical Sciences, Sari, Iran } \\
\end{array}$ & \\
\hline
\end{tabular}

\begin{tabular}{lll}
\hline Narges & Immunogenetics Research & $\begin{array}{l}\text { Gathered data, reviewed } \\
\text { Karimi, MD }\end{array}$ \\
& $\begin{array}{l}\text { Center, Toxoplasmosis } \\
\text { Research Center, }\end{array}$ & $\begin{array}{l}\text { the manuscript for } \\
\text { intellectual content }\end{array}$ \\
& Mazandaran University of & \\
& Medical Sciences, Sari, Iran &
\end{tabular}

Rodrigo Department of Medicine, Gathered data, reviewed

Bagur, MD Division of Cardiology, the manuscript for Schulich School of Medicine intellectual content and Dentistry, Western University, Ontario, Canada

\begin{tabular}{|c|c|c|}
\hline $\begin{array}{l}\text { Derek B. } \\
\text { Debicki, } \\
\text { MD }\end{array}$ & $\begin{array}{l}\text { Department of Clinical } \\
\text { Neurologic Sciences, } \\
\text { London Health Sciences } \\
\text { Center, Western University, } \\
\text { Ontario, Canada }\end{array}$ & $\begin{array}{l}\text { Gathered data, reviewed } \\
\text { the manuscript for } \\
\text { intellectual content }\end{array}$ \\
\hline $\begin{array}{l}\text { Teneille E. } \\
\text { Gofton, MD }\end{array}$ & $\begin{array}{l}\text { Department of Clinical } \\
\text { Neurologic Sciences, } \\
\text { London Health Sciences } \\
\text { Center, Western University, } \\
\text { Ontario, Canada }\end{array}$ & $\begin{array}{l}\text { Gathered data, reviewed } \\
\text { the manuscript for } \\
\text { intellectual content }\end{array}$ \\
\hline $\begin{array}{l}\text { David A. } \\
\text { Steven, } \\
\text { MD, MPH }\end{array}$ & $\begin{array}{l}\text { Department of Clinical } \\
\text { Neurologic Sciences, } \\
\text { London Health Sciences } \\
\text { Center, Western University, } \\
\text { Ontario, Canada }\end{array}$ & $\begin{array}{l}\text { Gathered data, reviewed } \\
\text { the manuscript for } \\
\text { intellectual content }\end{array}$ \\
\hline $\begin{array}{l}\text { Luciano A. } \\
\text { Sposato, } \\
\text { MD, MBA }\end{array}$ & $\begin{array}{l}\text { Department of Clinical } \\
\text { Neurologic Sciences, } \\
\text { London Health Sciences } \\
\text { Center, Western University, } \\
\text { Ontario, Canada }\end{array}$ & $\begin{array}{l}\text { Designed and supervised } \\
\text { the study, planned the } \\
\text { statistical analysis, } \\
\text { performed the systematic } \\
\text { search, gathered data, } \\
\text { drafted the first } \\
\text { manuscript, and reviewed } \\
\text { the final version of the } \\
\text { manuscript for intellectual } \\
\text { content }\end{array}$ \\
\hline
\end{tabular}

\section{References}

1. Bikdeli B, Madhavan MV, Jimenez D, et al. COVID-19 and thrombotic or thromboembolic disease: implications for prevention, antithrombotic therapy, and followup. J Am Coll Cardiol 2020;75:2950-2973.

2. Beyrouti R, Adams ME, Benjamin L, et al. Characteristics of ischaemic stroke associated with COVID-19. J Neurol Neurosurg Psychiatry 2020;91:889-891. 
3. Oxley TJ, Mocco J, Majidi S, et al. Large-vessel stroke as a presenting feature of COVID-19 in the young. N Engl J Med 2020;382:e60.

4. Schünemann HJ, Cuello C, Akl EA, et al. Grade guidelines: 18: how ROBINS-I and other tools to assess risk of bias in nonrandomized studies should be used to rate the certainty of a body of evidence. J Clin Epidemiol 2019;111:105-114.

5. CDC. Symptoms of coronavirus. Available at: cdc.gov/coronavirus/2019-ncov/ symptoms-testing/symptoms.html?CDC_AA_refVal=https $\% 3 \mathrm{~A} \% 2 \mathrm{~F} \%$ 2Fwww.cdc.gov\%2Fcoronavirus\%2F2019-ncov\%2Fabout\%2Fsymptoms.html. Accessed June 4, 2020.

6. Ekker MS, Boot EM, Singhal AB, et al. Epidemiology, aetiology, and management of ischaemic stroke in young adults. Lancet Neurol 2018;17:790-801.

7. Valderrama EV, Humbert K, Lord A, Frontera J, Yaghi S. Severe acute respiratory syndrome coronavirus 2 infection and ischemic stroke. Stroke 2020;51:e124-e127.

8. Shah Sanjiv J, Katz Daniel H, Selvaraj S, et al. Phenomapping for novel classification of heart failure with preserved ejection fraction. Circulation 2015;131:269-279.

9. Hanson HA, Leiser CL, O'Neil B, et al. Harnessing population pedigree data and machine learning methods to identify patterns of familial bladder cancer risk. Cancer Epidemiol Biomarkers Prev 2020;29:918-926.

10. Wang X, Xu Y. An improved index for clustering validation based on silhouette index and Calinski-Harabasz index. IOP Conf Ser Mater Sci Eng 2019;569:052024.

11. Karimi N, Sedaghat Z, Baziboroun M, Sharifi-Razavi A. COVID-19 accompanied with intracerebral hemorrhage: a case series. Arch Clin Infect Dis EPub 2020 October 7.

12. Sharifi-Razavi A, Karimi N, Zarvani A, Cheraghmakani H, Baghbanian S. Ischemic stroke associated with novel coronavirus 2019: a report of three cases. Int J Neurosience $2020 ; 17: 1-5$

13. Klok FA, Kruip MJHA, van der Meer NJM, et al. Incidence of thrombotic complications in critically ill ICU patients with COVID-19. Thromb Res 2020;191:145-147.

14. Helms J, Kremer S, Merdji H, et al. Neurologic features in severe SARS-CoV-2 infection. N Engl J Med 2020;382:2268-2270.

15. Li Y, Li M, Wang M, et al. Acute cerebrovascular disease following COVID-19: a single center, retrospective, observational study. Stroke Vasc Neurol 2020;5:279-284.

16. Beun R, Kusadasi N, Sikma M, Westerink J, Huisman A. Thromboembolic events and apparent heparin resistance in patients infected with SARS-CoV-2. Int $\mathrm{J}$ Lab Hematol 2020;42(suppl 1):19-20.

17. Lu L, Xiong W, Liu D, et al. New onset acute symptomatic seizure and risk factors in coronavirus disease 2019: a retrospective multicenter study. Epilepsia 2020;61: e49-e53.

18. Regina J, Papadimitriou-Olivgeris M, Burger R, et al. Epidemiology, risk factors and clinical course of SARS-CoV-2 infected patients in a Swiss university hospital: an observational retrospective study. medRxiv 2020. doi: 10.1101/2020.05.11.20097741

19. Rudilosso S, Laredo C, Vera V, et al. Acute stroke care is at risk in the era of COVID19: experience at a comprehensive stroke center in Barcelona. Stroke 2020;51: 1991-1995.

20. Romero-Sanchez CM, Diaz-Maroto I, Fernandez-Diaz E, et al. Neurologic manifestations in hospitalized patients with COVID-19: the ALBACOVID registry. Neurology 2020;95:e1060-e1070.

21. Lodigiani C, Iapichino G, Carenzo L, et al. Venous and arterial thromboembolic complications in COVID-19 patients admitted to an academic hospital in Milan, Italy. Thromb Res 2020;191:9-14.

22. Merkler AE, Parikh NS, Mir S, et al. Risk of ischemic stroke in patients with Covid-19 versus patients with influenza. medRxiv 2020. doi: 10.1101/ 2020.05.18.20105494.

23. Tsai LK, Hsieh ST, Chang YC. Neurological manifestations in severe acute respiratory syndrome. Acta Neurol Taiwan 2005;14:113-119.

24. Walkey AJ, Wiener RS, Ghobrial JM, Curtis LH, Benjamin EJ. Incident stroke and mortality associated with new-onset atrial fibrillation in patients hospitalized with severe sepsis. JAMA 2011;306:2248-2254.
25. Merkler AE, Parikh NS, Mir S, et al. Risk of ischemic stroke in patients with COVID19 versus patients with influenza. medRxiv 2020:2020.05.18.20105494.

26. Deliwala S, Abdulhamid S, Abusalih MF, Al-Qasmi MM, Bachuwa G. Encephalopathy as the sentinel sign of a cortical stroke in a patient infected with coronavirus disease-19 (COVID-19). Cureus 2020;12:e8121.

27. Salerno M, Sessa F, Piscopo A, et al. No autopsies on COVID-19 deaths: a missed opportunity and the lockdown of science. J Clin Med 2020;9:1472.

28. ACR guidance on COVID-19 and MR use. Available at: acr.org/Clinical-Resources/ Radiology-Safety/MR-Safety/COVID-19-and-MR-Use. Accessed June 4, 2020.

29. Bres Bullrich M, Fridman S, Mandzia JL, et al. COVID-19: stroke admissions, emergency department visits, and prevention clinic referrals. Can J Neurol Sci Epub 2020 May 26.

30. Ntaios G, Michel P, Georgiopoulos G, et al. Characteristics and outcomes in patients with COVID-19 and acute ischemic stroke. Stroke 2020;51:e254-e258.

31. Béjot Y, Bailly H, Durier J, Giroud M. Epidemiology of stroke in Europe and trends for the 21st century. Presse Med 2016;45:e391-e398.

32. Lan MY, Wu SJ, Chang YY, Chen WH, Lai SL, Liu JS. Neurologic and non-neurologic predictors of mortality in ischemic stroke patients admitted to the intensive care unit. J Formos Med Assoc 2006;105:653-658.

33. Cho SH, Yun SC. Bed-to-nurse ratios, provision of basic nursing care, and in-hospital and 30-day mortality among acute stroke patients admitted to an intensive care unit: cross-sectional analysis of survey and administrative data. Int J Nurs Stud 2009; 46:1092-1101.

34. Pongmoragot J, Rabinstein AA, Nilanont Y, Swartz RH, Zhou L, Saposnik G. Pulmonary embolism in ischemic stroke: clinical presentation, risk factors, and outcome. J Am Heart Assoc 2013;2:e000372.

35. Fabre O, Rebet O, Carjaliu I, Radutoiu M, Gautier L, Hysi I. Severe acute proximal pulmonary embolism and COVID-19: a word of caution. Ann Thorac Surg Epub 2020 Apr 16.

36. Horowitz JM, Yuriditsky E, Henderson IJ, Stachel MW, Kwok B, Saric M. Clot in transit on transesophageal echocardiography in a prone patient with COVID-19 acute respiratory distress syndrome. CASE (Phila) 2020;4:200-203.

37. Duloquin G, Graber M, Garnier L, et al. Incidence of acute ischemic stroke with visible arterial occlusion: a population-based study (Dijon Stroke Registry). Stroke 2020;51: 2122-2130.

38. Zhu J, Zhong Z, Ji P, et al. Clinicopathological characteristics of 8697 patients with COVID-19 in China: a meta-analysis. Fam Med Community Health 2020;8: e000406.

39. Viguier A, Delamarre L, Duplantier J, Olivot JM, Bonneville F. Acute ischemic stroke complicating common carotid artery thrombosis during a severe COVID-19 infection. J Neuroradiol 2020;47:393-394.

40. Le Berre A, Marteau V, Emmerich J, Zins M. Concomitant acute aortic thrombosis and pulmonary embolism complicating COVID-19 pneumonia. Diagn Interv Imaging 2020;101:321-322.

41. Lushina N, Kuo JS, Shaikh HA. Pulmonary, cerebral, and renal thromboembolic disease in a patient with COVID-19. Radiology 2020;296:E181-E183.

42. McCarthy CP, Raber I, Chapman AR, et al. Myocardial injury in the era of highsensitivity cardiac troponin assays: a practical approach for clinicians. JAMA Cardiol 2019;4:1034-1042.

43. Broersen LHA, Stengl H, Nolte $\mathrm{CH}$, et al. Association between high-sensitivity cardiac troponin and risk of stroke in 96702 individuals: a meta-analysis. Stroke 2020;51: 1085-1093.

44. Scheitz JF, Nolte CH, Laufs U, Endres M. Application and interpretation of highsensitivity cardiac troponin assays in patients with acute ischemic stroke. Stroke 2015; 46:1132-1140.

45. Puntmann VO, Carerj ML, Wieters I, et al. Outcomes of cardiovascular magnetic resonance imaging in patients recently recovered from coronavirus disease 2019 (COVID-19). JAMA Cardiol Epub 2020 Jul 27. 


\section{Neurology}

\section{Stroke risk, phenotypes, and death in COVID-19: Systematic review and newly reported cases \\ Sebastian Fridman, Maria Bres Bullrich, Amado Jimenez-Ruiz, et al.}

Neurology 2020;95;e3373-e3385 Published Online before print September 15, 2020

DOI 10.1212/WNL.0000000000010851

This information is current as of September 15, 2020

\section{Updated Information \&} Services

References

Citations

Subspecialty Collections

Permissions \& Licensing

Reprints including high resolution figures, can be found at: http://n.neurology.org/content/95/24/e3373.full

This article cites 38 articles, 10 of which you can access for free at: http://n.neurology.org/content/95/24/e3373.full\#ref-list-1

This article has been cited by 1 HighWire-hosted articles: http://n.neurology.org/content/95/24/e3373.full\#\#otherarticles

This article, along with others on similar topics, appears in the following collection(s):

\section{All Cerebrovascular disease/Stroke}

http://n.neurology.org/cgi/collection/all_cerebrovascular_disease_strok e

Critical care

http://n.neurology.org/cgi/collection/critical_care

Prognosis

http://n.neurology.org/cgi/collection/prognosis

Viral infections

http://n.neurology.org/cgi/collection/viral_infections

Information about reproducing this article in parts (figures,tables) or in its entirety can be found online at:

http://www.neurology.org/about/about_the_journal\#permissions

Information about ordering reprints can be found online:

http://n.neurology.org/subscribers/advertise

Neurology ${ }^{\circledR}$ is the official journal of the American Academy of Neurology. Published continuously since 1951, it is now a weekly with 48 issues per year. Copyright @ 2020 American Academy of Neurology. All rights reserved. Print ISSN: 0028-3878. Online ISSN: 1526-632X.

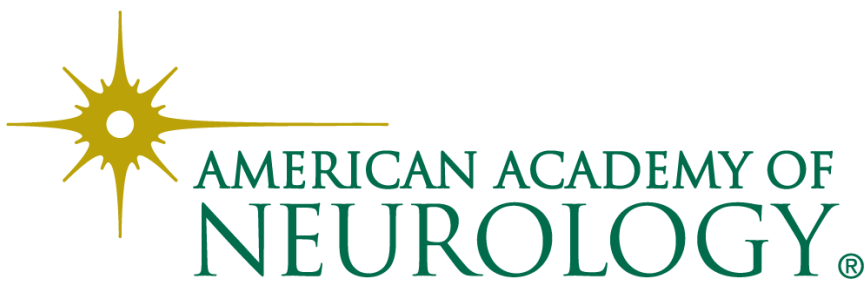

